\title{
NULIDAD E INEXISTENCIA DE LOS ACTOS JURÍDICOS EN EL DERECHO ECUATORIANO (II)
}

NULLITY AND INEXISTENCE OF LEGAL ACTS IN ECUADORIAN LAW

\author{
César Coronel Jones ${ }^{*}$ \\ Óscar Del Bruto Andrade ${ }^{* *}$
}

Resumen: La inexistencia y la nulidad son instituciones fundamentales para el derecho privado ecuatoriano. Se trata de dos categorías distintas que tienen en común perseguir la ineficacia de los actos que no se formaron de acuerdo a los parámetros jurídicos. Tratándose de actos inexistentes, la ley los priva de toda consecuencia jurídica. Tratándose de actos nulos, la ley permite que un juez declare su invalidez y desconozca sus efectos. Este artículo revisa la regulación legal de la inexistencia y la nulidad en el derecho ecuatoriano, así como los pronunciamientos al respecto de la Corte Nacional de Justicia.

Palabras clave: Actos jurídicos, ineficacia, inexistencia, nulidad absoluta, nulidad relativa

Abstract: Inexistence and nullity of juridical acts are basic institutions in Ecuadorian Law. These are two different categories that have in common the chasing of the invalidity of the juridical acts that didn't form according to Law. Inexistent acts are deprived by the law of any legal effect, while null acts have legal effects but a judge can declare them null and erase their legal effects that have already taken place. This paper reviews the legal regulation of inexistent and nullity under

* Profesor de Derecho Civil en la Universidad Católica Santiago de Guayaquil (Ecuador).ccoronel@coronelyperez.com

** Ayudante de la cátedra de Responsabilidad Civil en la Universidad Católica Santiago de Guayaquil (Ecuador). oscar_delbrutto@hotmail.com 
Ecuadorian Law, as well as the rulings of the National Court of Justice regarding the issue.

Key words: Juridical acts, inefficiency, inexistence, nullity, absolute nullity, relative nullity

Fecha de recepción: 28-11-2011

Fecha de aceptación: 15-12-2011

Fecha de publicación electrónica: 05-01-2013

Sumario. 4. Nulidad relativa. 4.1. Fundamentos de la nulidad relativa. 4.2. Causales de nulidad relativa. 4.2.1. Vicios de la voluntad. 4.2.2. Lesión enorme. 4.3.3. Inobservancia de requisitos legales. 4.2.4. Actos de los incapaces relativos. 4.3. Legitimidad para solicitar la nulidad relativa. 4.4. Saneamiento y prescripción de la nulidad relativa. 5. La nulidad que produce un acto prohibido por la ley. 6. Efectos de la declaratoria judicial de nulidad. 6.1. Sentencia que declara la nulidad de un acto. 6.2. Efectos de la nulidad entre las partes. 6.3. Efectos de la nulidad con respecto a terceros. 7. Conclusiones. Referencias.

En la primera parte de este artículo nos detuvimos en el análisis de la inexistencia y de la nulidad absoluta de actos jurídicos en el derecho ecuatoriano. Ahora abordaremos el tema de la nulidad relativa, haremos una mención especial a la nulidad que se produce por el acto que es prohibido por la ley y, finalmente, hablaremos sobre los efectos de la declaratoria judicial de nulidad (efectos que, según veremos, son comunes a la nulidad absoluta y a la nulidad relativa).

\section{NULIDAD RELATIVA}

\subsection{Fundamento de la nulidad relativa}

La nulidad relativa es una sanción de ineficacia impuesta al acto que no cumple con requisitos de validez, cuando esos Ius Humani, v. 3 (2012/13), p. 78 
requisitos han sido establecidos en consideración al interés particular de las personas que celebran el acto (Ospina \& Ospina, 2000, págs. 459-460; Claro, 1979, pág. 613; Vodanovic, 1961, pág. 328; Alessandri Besa, 2011, pág. 9). Así entendida, la nulidad relativa es un beneficio que se otorga a ciertas personas que la ley considera necesitadas de protección. Este beneficio permite a la persona protegida evadir el cumplimiento de la obligación que contrajo y hacer que se regrese al mismo estado de cosas que había antes de que se celebre el acto ${ }^{1}$.

Existe una diferencia de fundamento entre la nulidad relativa y la nulidad absoluta: mientras ésta se erige como una institución que sirve para la defensa de intereses generales, aquella se nos muestra como la protección legislativa a intereses privados (Vélez, 1924, págs. 405-406; Ospina \& Ospina, 2000, págs. 459-460; Claro, 1979, pág. 619; Vodanovic, 1961, pág. 328; Alessandri Besa, 2011, pág. 11). Con la nulidad relativa no se persigue la protección de intereses generales, sino que se busca evitar el desequilibrio que supondría la intervención de una persona poco informada o poco preparada en la celebración de un acto jurídico (Ospina \& Ospina, 2000, pág. 460).

El término "relativa" es usado para indicar que el acto es nulo para una de las partes pero no para la otra. En efecto, un acto nulo relativamente es válido para una de las partes del acto, pero nulo para la otra parte, para la parte a favor de la cual ha sido establecida la nulidad (Baraona González, 2012, págs. 66-67).

La circunstancia de que la nulidad relativa tenga un diferente fundamento al de la nulidad absoluta determina ciertas diferencias entre su régimen y el de la nulidad absoluta (Alessandri Besa, 2011, págs. 11-12). Este régimen se refiere, básicamente, a las causales por las cuales procede la nulidad

\footnotetext{
${ }^{1}$ El carácter de "beneficio" de la nulidad relativa está reconocido en el artículo 1700 del Código Civil, que señala que la nulidad relativa puede alegarse "por aquellos en cuyo beneficio" se ha establecido. Alessandri Besa ha destacando el carácter de beneficio de la nulidad relativa (2011, pág. 11).
} 
relativa, a las personas que están legitimadas para solicitar que se declare la nulidad relativa de un acto, y al saneamiento y prescripción de la nulidad relativa.

\subsection{Causales de nulidad relativa}

En el derecho ecuatoriano, la nulidad relativa es la regla general y subsidiaria. Por tanto, cualquier violación a un requisito legal establecido para la validez del acto que no sea de los expresamente enunciados como causales de nulidad absoluta, causará la nulidad relativa ${ }^{2}$.

La doctrina ha enumerado las causales de nulidad relativa. Según esta enumeración, la nulidad relativa se produce en casos en los que una parte del acto jurídico se encuentra en una posición precaria o de inferioridad. Así, hay nulidad relativa: a) en los casos en que la voluntad generadora del acto ha estado viciada; b) en los casos de lesión enorme; c) en los casos en los que se omiten formalidades exigidas en consideración al estado o calidad de las personas que celebran el acto; $\mathrm{y}, \mathrm{d}$ ) en los casos en los que el acto ha sido celebrado por incapaces relativos (Valencia \& Ortiz, 2000, pág. 526; Claro, 1979, págs. 612-618; Vodanovic, 1961, págs. $328-329)^{3}$.

\subsubsection{Vicios de la voluntad}

Para el derecho ecuatoriano, la voluntad está viciada cuando ha sido otorgada sin libertad o sin el mínimo nivel de conocimiento (Ospina \& Ospina, 2000, pág. 179; Vodanovic,

\footnotetext{
${ }^{2}$ Esta conclusión se sigue del artículo 1698 del Código Civil que, en su parte pertinente, dice que "[c]ualquier otra especie de vicio produce nulidad relativa”. En el sentido de que la nulidad relativa es la regla general y subsidiaria cfr. Vélez (1924, pág. 402), Valencia \& Ortiz (2000, pág. 525), Ospina \& Ospina (2000, pág. 459), Claro (1979, pág. 613), Vodanovic (1961, pág. 328), Alessandri Besa (2011, págs. 17-18).

${ }^{3}$ Algunos autores añaden la lesión como causal de nulidad relativa (Ospina \& Ospina, 2000, pág. 460; Alessandri Besa, 2011, pág. 20).
}

Ius Humani, v. 3 (2012/13), p. 80 
1961, pág. 109). Por eso, el Código Civil establece que la voluntad de una persona que interviene en la celebración de un acto jurídico queda viciada por error, fuerza o dolo (artículo 1467).

El error es la disconformidad entre la idea y lo real (Ospina \& Ospina, 2000, pág. 181; Vodanovic, 1961, pág. 110). Hay error si una persona tiene la idea de que una barra es de plata cuando en realidad es de algún otro metal (este es el ejemplo de error sustancial que trae el artículo 1470 del Código Civil). Según el Código Civil, el error es vicio de voluntad cuando recae sobre una calidad esencial del objeto del acto, o sobre una calidad accidental que es tenida como esencial por las partes (artículo 1470), o sobre la persona con la que se realiza el acto si esa persona es determinante (artículo 1471). Así, hay error en el contrato de compraventa del café que se cree colombiano cuando en realidad es brasileño, porque la procedencia es una calidad esencial del café; hay error en la venta de un traje que se creía de Michael Jackson y que en realidad era de un desconocido, cuando el vendedor y el comprador sabían que haber sido de Michael Jackson era la principal razón para comprar el traje, porque se trata de una calidad accidental que las partes han tenido por esencial; y, hay error en el contrato de arrendamiento de servicios con un abogado que no es el que se pensaba, porque la calidad de la persona es determinante en esta clase de contratos. Para saber si la calidad del objeto es esencial o no, o si la persona es determinante para celebrar el acto, debe estarse a la intención subjetiva de las partes (Alessandri Besa, 2011, pág. 30) ${ }^{4}$.

La fuerza es la presión física o moral que se ejerce sobre una persona y que tiene por efecto reducir ilegítimamente sus opciones de acción (Ospina \& Ospina, 2000, pág. 212; Vodanovic, 1961,

\footnotetext{
${ }^{4}$ En contra Guillermo y Eduardo Ospina, para quienes las calidades esenciales se aprecian objetivamente (2000, págs. 190-194).
} 
págs. 135-137; Alessandri Besa, 2011, págs. 45-46) ${ }^{5}$. Para que la fuerza vicie el consentimiento, el artículo 1472 del Código Civil exige que ésta sea injusta, grave y determinante (Ospina \& Ospina, 2000, págs. 213-222; Vodanovic, 1961, págs. 138-145; Alessandri Besa, 2011, págs. 49-57). Que la fuerza sea injusta significa que no hay razón ni excusa que la justifique; que sea grave significa que es capaz de producir impresión en una persona tomando en cuenta sus circunstancias personales; que sea determinante significa que sin ella no se habría realizado el acto. Así, hay fuerza que vicia el consentimiento cuando Don Vito Corleone nos hace "una oferta que no podemos rechazar" porque nos dice que si no celebramos un contrato asesina a algún familiar nuestro. Pero, en cambio, no hay fuerza si nuestro acreedor nos amenaza con demandarnos o con no contratar en el futuro con nosotros, porque está en su derecho de hacerlo y no se entiende que la fuerza sea injusta ${ }^{6}$; tampoco hay fuerza si un adulto firma un contrato porque un niño de cuatro años lo amenaza con golpearlo, porque en tal caso la fuerza no es grave; tampoco hay fuerza en el empujón que da un trabajador de la estación de trenes a un pasajero para que embarque rápido al tren, porque sin esa fuerza el pasajero hubiera subido de todos modos y no es, por tanto, determinante.

Para que la fuerza vicie el consentimiento no es necesario que la ejerza aquel que se beneficia del acto, sino que basta que

\footnotetext{
${ }^{5}$ Según una opinión, en casos de fuerza física no hay vicio de voluntad sino que la voluntad no se produce en lo absoluto. Un análisis del tema lo hace Alessandri Besa (2011, págs. 47-49).

${ }^{6}$ En este sentido, la Corte Nacional de Justicia señaló que no había fuerza en el testamento de un obispo religioso que, por disposición del Derecho Canónico, no podía dejar sus bienes a sus parientes sino que debía dejarlos a una entidad religiosa. Cfr. Romero et al. vs. Vicariato Apostólico del Puyo, 3 de octubre de 2000, Gaceta Judicial Serie XVII No. 4.
}

Ius Humani, v. 3 (2012/13), p. 82 
sea empleada por cualquier persona ${ }^{7}$. No se entiende que hay fuerza, sin embargo, en los casos de estado de necesidad, es decir, cuando nuestras opciones se han reducido, no por el hecho del hombre, sino por un hecho de la naturaleza o por calamidades de la vida (Alessandri Besa, 2011, pág. 50; Vodanovic, 1961, págs. 145-146) ${ }^{8}$. Por tanto, no hay vicio de consentimiento si alguien se ve en la imperiosa necesidad de vender su vehículo para pagar los gastos médicos de un familiar gravemente accidentado.

El dolo es la intención de inferir daño a la persona o a los bienes de otro ${ }^{9}$. Como vicio del consentimiento, el dolo consiste en maquinaciones utilizadas para conducir a una persona error (Ospina \& Ospina, 2000, pág. 202; Vodanovic, 1961, págs. 150151; Alessandri Besa, 2011, págs. 62-63). Para que el dolo vicie la voluntad, el Código Civil exige que sea obra de una de las partes y que sin él no se hubiera celebrado el acto (artículo 1474 del Código Civil) ${ }^{10}$. Así, hay nulidad relativa por vicio del consentimiento en el caso de una persona que otorga un préstamo engañada por otra que se le presenta como comerciante solvente y próspero sin serlo, engañándolo con documentos y testigos falsos, pues una de las partes conduce a error a la otra y sin el engaño no hubiera habido contrato.

\subsubsection{Lesión enorme}

Se entiende por lesión el desbalance económico que sufre una persona como consecuencia de un intercambio patrimonial.

${ }^{7}$ Cfr. artículo 1473 del Código Civil. En este sentido, Ospina \& Ospina (2000, págs. 217-218), Vodanovic (1961, págs. 146-147), Alessandri Besa (2011, pág. $52)$.

${ }^{8}$ En contra Ospina \& Ospina (2000, págs. 218-219).

${ }^{9}$ Artículo 29 del Código Civil. Cfr. Carbo et al. vs. Vergara et al., 18 de abril de 2007, Gaceta Judicial Serie XVIII No. 5.

${ }^{10}$ Según se ha fallado, un acto unilateral no puede estar viciado por dolo, porque para que exista este vicio debe haber dos partes del acto, una engañando a la otra. Cfr. Carbo et al. vs. Vergara et al., 18 de abril de 2007, Gaceta Judicial Serie XVIII No. 5. En contra Vodanovic (1961, págs. 168-169). 
La lesión enorme se refiere a una grave desproporción entre la ventaja del acto y el sacrificio que ese acto reporta (Ospina \& Ospina, 2000, págs. 285-295; Vodanovic, 1961, págs. 170-180; Alessandri Besa, 2011, págs. 72-82). Así, por ejemplo, hay lesión enorme para el comprador que paga diez por una cosa cuyo precio real es dos ${ }^{11}$.

En el Ecuador, la lesión no es un vicio del consentimiento ${ }^{12}$, ni una regla de carácter general (Ospina \& Ospina, 2000, pág. 289; Vodanovic, 1961, pág. 172; Alessandri Besa, 2011, pág. 73). Se trata de un desbalance en el resultado de un acto jurídico que tiene que ser evaluado de manera objetiva y que sólo se permite en un reducido número de actos. En efecto, como ha recalcado la Corte Nacional de Justicia, para determinar la lesión se hace una simple operación matemática, sin necesidad de atender a la condición subjetiva de los contratantes ${ }^{13}$. La lesión enorme resulta de determinar de manera cierta el precio que una cosa tuvo al momento del acto y ver si ese precio era sustancialmente inferior o superior al justo precio. Además, la lesión sólo se produce en los casos expresamente señalados por la ley, a saber: la compraventa y la permuta de bienes inmuebles, la partición de bienes, la aceptación de una asignación sucesoral, y la cláusula penal

${ }^{11}$ Como se ve, en este punto, el Código Civil ha tomado una posición de teoría económica muy cercana al marxismo, bajo la creencia de que los precios pueden ser determinados objetivamente y que el valor de las cosas no es subjetivo.

${ }^{12}$ Cfr. Paucar et al. vs Cruz, 22 de julio de 2002, Gaceta Judicial Serie XVII No. 10; Ospina \& Ospina (2000, pág. 294), Vodanovic (1961, págs. 171-172); Alessandri Besa (2011, págs. 72-73).

${ }^{13}$ Cfr. Paucar et al. vs Cruz, 22 de julio de 2002, Gaceta Judicial Serie XVII No. 10; Montaño vs Montaño, 16 de septiembre de 2004, Gaceta Judicial Serie XVIII No. 1. En este último caso, la Corte destacó que el justo precio se refiere al momento del contrato y que si después aumenta el valor de la cosa, este aumento no se deberá tomar en cuenta. Además, en otro caso, la Corte señaló que debe existir certeza absoluta del precio al momento del acto y que si eso no ocurre, por ser simulado el precio, no cabía entrara a determinar si había lesión, Romo vs. Brito et al., 12 de julio de 2004, Gaceta Judicial Serie XVII No. 15.

Ius Humani, v. 3 (2012/13), p. 84 
(Ospina \& Ospina, 2000, pág. 285; Vodanovic, 1961, págs. 172182; Alessandri Besa, 2011, págs. 76-86) ${ }^{14}$. No se trata de una regla de carácter general, sino que se reduce a estos actos expresamente señalados por el Código Civil.

Dependiendo del acto que haya producido la lesión, el Código Civil manda o a que se anule el acto o a que se autorice al juez a reducir la lesión y que se persevere el contrato ${ }^{15}$. Así, la sanción de la lesión es, o la nulidad relativa del acto, o la reducción a los términos razonables de las estipulaciones del acto que produjeron la lesión enorme (Vodanovic, 1961, pág. 174).

\subsubsection{Inobservancia de requisitos legales}

También es causal de nulidad relativa la inobservancia de requisitos que la ley ha establecido en consideración a las personas que celebran el acto $^{16}$. Se trata de casos en los que la ley

${ }^{14}$ Con respecto a la compraventa de inmuebles, la Corte Nacional de Justicia ha dicho que no procede lesión si la venta se hace por el ministerio de la justicia (cfr. Heredia vs. Cervantes et al., 24 de abril de 2006, Gaceta Judicial Serie XVIII No. 2.); y, la lesión sí procede en la venta de cuotas de derechos sobre inmuebles (cfr. Zamora vs. Zamora, 23 de abril de 1998, Gaceta Judicial Serie XVI No. 12; Ortega et al vs. Burgos, 15 de septiembre de 1998, Gaceta Judicial Serie XVI No. 13).

${ }^{15}$ Para el caso de la compraventa, se permite al vencido en juicio decidir si anular el contrato o perseverar en él haciendo las correcciones pertinentes, según lo indicado en el artículo 1830 del Código Civil. Lo mismo ocurre para el caso de la permuta, pues, como se sabe, en virtud de lo prescrito en el artículo 1840 del Código Civil, lo previsto para la compraventa se aplica a la permuta. En el caso de la partición de bienes, el artículo 1366 del Código Civil, permite a los otros partícipes "atajar" la nulidad de la partición por lesión enorme ofreciendo al perjudicado el suplemento. En el caso de la aceptación de asignación sucesoral sólo procede la nulidad en virtud de lo dispuesto en el artículo 1257 del Código Civil, mientras que en la cláusula penal sólo procede el reajuste del acto lesivo, y no su nulidad, según lo establecido en el artículo 1560 del Código Civil.

${ }^{16}$ Esta causal se desprende de una interpretación contrariu sensu del artículo 1698 del Código Civil. 
ha previsto un requisito de forma o de fondo para la celebración de un determinado acto con el objeto de precautelar los intereses de una de las partes del acto, y tal requisito es inobservado. Así, por ejemplo, hay nulidad relativa en los actos de disposición de bienes de la sociedad conyugal que hace el marido sin el consentimiento de la mujer ${ }^{17}$.

\subsubsection{Actos de los incapaces relativos}

Adolecen de nulidad relativa los actos celebrados por los incapaces relativos ${ }^{18}$. En el derecho ecuatoriano adolecen de incapacidad relativa los menores adultos, los disipadores en interdicción judicial y las personas jurídicas (cfr. artículo 1463 del Código Civil). La ley considera que no están en condición de intervenir en la vida jurídica y, por tanto, aspira a protegerlos. Estas personas deben actuar representadas o autorizadas por su representante legal $\mathrm{y}$, cuando no lo hacen, dichos actos adolecen de nulidad relativa.

Según el Código Civil, hay ciertas incapacidades particulares, que son establecidas legalmente para prohibir a ciertas personas la celebración de ciertos actos (cfr. artículo 1463 del Código Civil). Este tipo de incapacidades particulares por regla general serán causal de nulidad relativa, pero tiene que indagarse la razón de la prohibición, y si se trata de una prohibición que tiene en miras el orden público entonces habrá nulidad absoluta, mientras que si se trata de una prohibición que

17 Artículo 1700 del Código Civil. En este sentido, cfr. Chela vs. Rea. 11 de diciembre de 1996, Gaceta Judicial Serie XVI No. 7; Ojeda vs. Luna et al., 3 de febrero de 2004, Gaceta Judicial Serie XVII No. 15. En un desconcertante caso, la Corte Nacional de Justicia ha dicho que la parte del Código Civil que declara la nulidad relativa de los actos realizados por un cónyuge sin la autorización del otro cuando ésta es requerida, no aplica cuando se dispone de las acciones y derechos que podrían tenerse sobre el inmueble, y no del inmueble en sí (cfr. Arévalo et al. vs. Arévalo et al., 4 de junio de 2004, Gaceta Judicial Serie XVIII No. 1).

${ }^{18}$ Se desprende del artículo 1698 del Código Civil.

Ius Humani, v. 3 (2012/13), p. 86 
se refiere al interés particular de quien participa en el acto, habrá nulidad relativa (Ospina \& Ospina, 2000, págs. 96-97; Claro, 1979, pág. 614).

\subsection{Legitimidad para solicitar la nulidad relativa}

Según el artículo 1700 del Código Civil, están legitimados para pedir que se declare la nulidad relativa de un acto: a) las personas en cuyo beneficio han establecido las leyes la nulidad relativa; b) sus herederos; y, c) sus cesionarios (Vélez, 1924, págs. 409-410; Ospina \& Ospina, 2000, pág. 460; Claro, 1979, pág. 620; Vodanovic, 1961, págs. 329-330; Alessandri Besa, 2011, pág. 185$)^{19}$.

La legitimación no aplica para todos los que intervienen en el acto, sino sólo para aquellos que la ley busca proteger, sus herederos y cesionarios (Claro, 1979, págs. 620-621; Vodanovic, 1961, pág. 329; Alessandri Besa, 2011, pág. 185) ${ }^{20}$. Si un adulto contrata con un niño de diez años, el niño puede solicitar la nulidad relativa, pero no el adulto. Según hemos dicho, esa es precisamente la razón por la que se llama nulidad "relativa", porque el acto es nulo para unos y válido para otros.

Como la nulidad relativa no se propone tutelar el interés general de la sociedad, sino intereses particulares, la ley no permite que la nulidad relativa sea declarada de oficio por el juez, ni que sea solicitada por el Ministerio Público en el sólo interés de la moral ${ }^{21}$.

${ }^{19}$ Para el caso en que la nulidad beneficie a una compañía anónima, la Corte Nacional de Justicia ha dicho que puede alegar la nulidad relativa el representante de la compañía, pero no sus accionistas individualmente considerados (cfr. Toledo vs. Sicomesa, 13 de abril de 1998, Gaceta Judicial Serie XVI No. 11).

${ }^{20}$ No parece ser el criterio de Fernando Vélez (1924, pág. 413).

${ }^{21}$ Cfr. artículo 1700 del Código Civil. En este sentido, Vélez (1924, pág. 409), Valencia \& Ortiz (2000, págs. 526-527), Ospina \& Ospina (2000, pág. 460), Claro (1979, págs. 619-620), Vodanovic (1961, pág. 329), Alessandri Besa (2011, págs. 184-185). 
Las personas en cuyo beneficio la ley ha establecido la nulidad relativa varían dependiendo de la causal de nulidad. En el caso de los actos en cuyo perfeccionamiento ha intervenido la voluntad viciada de una de las partes, la ley sólo permite solicitar la nulidad a la víctima del vicio. Por tanto, puede pedir la nulidad relativa el que dio su consentimiento en base a un error, el que fue coaccionado y el que fue engañado por su contraparte. En el caso de los actos realizados por incapaces relativos, serán éstos los legitimados para solicitar la nulidad, quienes, si siguen siendo incapaces al tiempo de solicitar la nulidad, deberán obrar a través de sus representantes. Cuando el incapaz ha obrado dolosamente en la celebración del acto, el Código Civil le prohíbe solicitar la nulidad (artículo 1701). Finalmente, en el caso de haberse omitido formalidades prescritas en consideración a la calidad o estado de la persona, sólo está legitimado para solicitar la nulidad la persona a quien la ley ha buscado proteger al establecer las formalidades.

En segundo lugar, también están legitimados para solicitar la nulidad relativa los herederos de las personas en cuyo beneficio ha establecido la ley la nulidad. Pueden alegar la nulidad los herederos de las personas víctimas de error, fuerza o dolo; los herederos de los incapaces relativos; y, los herederos de las personas en cuyo favor la ley ha establecido formalidades que fueron desconocidas.

Para que proceda la legitimación es necesario que los herederos hayan aceptado la herencia, pues entonces se entiende que son los continuadores de la personalidad del beneficiado y que lo suceden en todos los derechos y obligaciones transmisibles. Por otro lado, si la persona en cuyo beneficio se ha establecido el derecho de alegar la nulidad lo pierde, tampoco podrán alegar la nulidad relativa sus herederos. Tienen derecho de alegar la nulidad tanto los herederos directos como los herederos de los herederos.

Por último, también están facultados para pedir la nulidad relativa los cesionarios de las personas en cuyo beneficio la han 
establecido las leyes. Según una opinión, se trata de los cesionarios del derecho de alegar la nulidad relativa. Según otra opinión, además de los cesionarios del derecho de alegar, también están legitimados los cesionarios de los derechos y acciones que emanen del acto nulo. Al igual que ocurre con los cesionarios, están legitimados para alegar la nulidad relativa tanto los cesionarios directos como los indirectos.

\subsection{Saneamiento y prescripción de la nulidad relativa}

Para el Código Civil (artículos 1700 y 1713), la persona que tiene derecho para alegar la nulidad relativa y hacer que se desconozcan los efectos del acto, tiene también el derecho para ratificar el acto nulo y purgarlo del vicio que lo invalidaba (Vélez, 1924, pág. 411; Valencia \& Ortiz, 2000, pág. 531; Ospina \& Ospina, 2000, pág. 481; Claro, 1979, pág. 641; Alessandri Besa, 2011, pág. 273; Vodanovic, 1961, pág. 332) 22 . La ratificación consiste en la renuncia de alegar la nulidad relativa, y tiene como consecuencia la validación del acto que originariamente fue nulo (Vélez, 1924, pág. 414; Ospina \& Ospina, 2000, pág. 480; Claro, 1979, pág. 640; Vodanovic, 1961, pág. 231; Alessandri Besa, 2011, págs. 260-262). La ratificación sólo procede una vez que el acto se ha perfeccionado pues, como vimos, la nulidad es una sanción a la que las partes no pueden renunciar anticipadamente (Alessandri Besa, 2011, pág. 261).

22 Se trata de una institución que sólo aplica a la nulidad relativa y que, de hecho, la define. En este sentido, la Corte Nacional de Justicia, que llegó a sostener que una manera de determinar si un acto adolecía de nulidad relativa o de nulidad absoluta era fijarse en si la ley permitía su ratificación. Así, concluyó que la falta de insinuación en la donación es causal de nulidad relativa y no de nulidad absoluta, precisamente porque el Código Civil permite ratificar el acto, haciendo la insinuación a posteriori (cfr. Aucapiña et al vs. Ministro de Educación y Cultura et al., 31 de enero de 2001, Gaceta Judicial Serie XVII No. 5; Mejía vs. Mejía et al., 28 de enero de 2003, Serie XVII No. 12). 
El artículo 1710 del Código Civil establece que la ratificación puede ser expresa o tácita (Vélez, 1924, pág. 414; Ospina \& Ospina, 2000, pág. 485; Claro, 1979, pág. 641; Vodanovic, 1961, pág. 332; Alessandri Besa, 2011, pág. 261; Valencia \& Ortiz, 2000, pág. 531). Hay ratificación expresa cuando la parte que puede alegar la nulidad relativa renuncia a su derecho de alegarla mediante un acto jurídico unilateral (Ospina \& Ospina, 2000, pág. 485; Claro, 1979, pág. 641; Vodanovic, 1961, pág. 332; Alessandri Besa, 2011, pág. 265 y 2902 ${ }^{23}$. Como acto jurídico que es, la ratificación tiene que cumplir con los elementos esenciales y de validez de todo acto jurídico (Alessandri Besa, 2011, pág. 276) ${ }^{24}$. En especial, el artículo 1711 del Código Civil exige que el acto de ratificación observe las mismas solemnidades que debió observar el acto que se ratifica (Claro, 1979, pág. 643; Alessandri Besa, 2011, pág. 293; Vélez, 1924, pág. 416; Vodanovic, 1961, pág. 332; Valencia \& Ortiz, 2000, pág. 531; Ospina \& Ospina, 2000, pág. 485). Por su parte, la ratificación es tácita cuando la persona que puede alegar la nulidad, ejecuta, total o parcialmente, las obligaciones del acto, siempre que esa ejecución sea voluntaria, esto es, con pleno conocimiento del vicio que invalida el acto (Vélez, 1924, pág. 416; Valencia \& Ortiz, 2000, pág. 531; Claro, 1979, pág. 642; Vodanovic, 1961, pág. 332 25.

\footnotetext{
${ }^{23}$ Fernando Vélez dice, a nuestro modo de ver de manera equivocada, que la ratificación es un nuevo "contrato" cuando, en realidad, se trata de un acto jurídico unilateral (1924, pág. 416).

${ }^{24} \mathrm{La}$ doctrina ha resaltado especialmente la necesidad de que no exista error, esto es, que no vale la ratificación en la que no se conoce el vicio que invalidaba al acto (Alessandri Besa, 2011, pág. 293).

${ }^{25}$ Cfr. artículo 1712 del Código Civil; Alessandri Besa, 2011, págs. 297-303. Guillermo y Eduardo Ospina se pronuncian en el sentido de que sólo cabe hablar de ratificación tácita cuando se ejecutan totalmente las obligaciones del acto nulo (2000, págs. 485-486).
}

Ius Humani, v. 3 (2012/13), p. 90 
Por otro lado, en el derecho ecuatoriano la nulidad relativa también puede sanearse por el paso del tiempo ${ }^{26}$. El Código Civil exige el transcurso de cuatro años para que prescriba el derecho de alegar la nulidad relativa (artículo 1708). Pasados estos cuatros años, el acto, que originariamente fue nulo, es tenido por válido desde el día en que se celebró (Claro, 1979, pág. 624; Vodanovic, 1961, pág. 330; Alessandri Besa, 2011, pág. 230) ${ }^{27}$. Por tanto, después del tiempo de cuatro años, la persona en cuyo beneficio estaba establecida la nulidad relativa, no podrá pedir que se declare la nulidad del acto ni como acción ni como excepción (Ospina \& Ospina, 2000, pág. 465; Alessandri Besa, 2011, pág. $230)^{28}$.

La manera de contar los cuatro años está especialmente prevista en el artículo 1708 del Código Civil. El Código aplica aquí la regla general en materia de prescripción extintiva, según la cual el plazo de prescripción se empieza a contar desde que la persona que puede alegar el derecho está en condición de alegarlo (Alessandri Besa, 2011, pág. 232). Por tanto, la regla es que los cuatros años se cuentan desde que se celebró el acto, a menos que haya una buena razón para empezar a contar desde otro momento (Claro, 1979, pág. 625).

${ }^{26}$ Cfr. artículo 1700 del Código Civil. Parecen apoyar esta afirmación las palabras de Vélez (1924, pág. 411), Valencia \& Ortiz (2000, pág. 530), Ospina \& Ospina (2000, pág. 465), Claro (1979, pág. 623), Vodanovic (1961, pág. 330) y Alessandri Besa (2011, pág. 230).

${ }^{27}$ Guillermo y Eduardo Ospina enfatizan que no se trata de una simple prescripción de alegar la nulidad, sino de una verdadera purgación del vicio que invalidaba el acto (2000, págs. 465-468).

${ }^{28}$ No aplica en Ecuador la regla de que "las excepciones no prescriben" (Ospina \& Ospina, 2000, pág. 466). Tanto la acción como la excepción sólo pueden ser solicitadas por quien está en el derecho de alegar la nulidad relativa. En contra Fernando Vélez, para quien la parte no beneficiada sí puede alegar la nulidad relativa como excepción (1924, pág. 413). Esta no parece ser la opinión predominante: véase lo dicho a propósito de la legitimación para solicitar la nulidad relativa. 
Según el artículo 1708 del Código Civil, si el vicio del consentimiento que anula el acto es la fuerza, deberá empezarse a contar el plazo desde que la fuerza ha cesado (Vélez, 1924, pág. 413; Ospina \& Ospina, 2000, pág. 566; Claro, 1979, pág. 625; Vodanovic, 1961, pág. 330; Alessandri Besa, 2011, pág. 233). Sería el caso de quien es privado de su libertad y amenazado para que firme un contrato de mutuo, pues sólo cuando recobre su libertad y no sienta la inminencia de la amenaza, empezará a contar el tiempo para el saneamiento del acto.

Otro supuesto en el que el Código Civil considera que hay una buena razón para apartarse de la regla de que el tiempo se cuenta desde que se celebró el acto, es el caso de que la nulidad sea consecuencia de que el acto fue celebrado por un incapaz relativo, pues, entonces, se empieza a contar desde que cesa la incapacidad $^{29}$. Así, por ejemplo, si un adolescente celebra un contrato de hipoteca de un bien raíz, el plazo para que se sanee ese contrato se empieza a contar desde que el adolescente cumpla la mayoría de edad.

Finalmente, una buena razón para no aplicar la regla general, es que una ley especialmente establezca otro plazo de

${ }^{29}$ Artículo 1708 del Código Civil. El artículo 1709 trae la aplicación de esta regla al caso de los herederos. (Vélez, 1924, págs. 413-414; Ospina \& Ospina, 2000, pág. 467; Claro, 1979, págs. 625-629; Vodanovic, 1961, págs. 330-331; Alessandri Besa, 2011, pág. 233) Parece que esta regla se aplica también a los menores impúberes, que son incapaces absolutos, pues se dice el artículo 1709 que a los herederos les corre el plazo desde que lleguen a la mayoría de edad pero, "en este caso no se podrá pedir la declaración de nulidad, pasados quince años desde la celebración del acto o contrato" (Ospina \& Ospina, 2000, pág. 467) y esos quince años sólo podría cumplirse en caso de que se haya empezado a contar desde que el menor era impúber, pues en Ecuador la mayoría de edad se alcanza a los dieciocho años. Según Alessandri Besa, el artículo 1709 se refiere a los incapaces absolutos pero sólo el acto en que intervinieron cause nulidad relativa (2011, pág. 233). En contra Vélez (1924, pág. 413).

Ius Humani, v. 3 (2012/13), p. 92 
prescripción de nulidad ${ }^{30}$. Como ha destacado la doctrina, a la prescripción del derecho de alegar la nulidad se le aplican ciertas reglas especiales de interrupción y suspensión de la prescripción (Ospina \& Ospina, 2000, págs. 467-468; Vodanovic, 1961, pág. 331; Alessandri Besa, 2011, págs. 244-257).

\section{LA NULIDAD QUE PRODUCE UN ACTO PROHIBIDO POR}

\section{LA LEY}

Una consideración especial merece la nulidad producida por los actos prohibidos por la ley.

En el Título Preliminar del Código Civil se encuentra una disposición redactada en términos bastante amplios que señala que los actos que prohíbe la ley son nulos a menos que la ley les designe expresamente otro efecto distinto al de la nulidad. Se trata del artículo 9 del Código Civil que, a la letra, prescribe que "[l]os actos que prohíbe la ley son nulos y de ningún valor; salvo en cuanto designe expresamente otro efecto que el de nulidad para el caso de contravención".

Las leyes pueden ser permisivas, imperativas y prohibitivas $^{31}$. Leyes permisivas son aquellas que autorizan a una persona a hacer o a no hacer algo, y, al mismo tiempo, imponen la obligación al resto de personas de no impedir que la persona beneficiada con la autorización haga o deja de hacer lo que se le permite. Así, por ejemplo, es una ley permisiva la disposición del Código Civil que autoriza al mandante a revocar el mandato y dar por terminado el contrato unilateralmente (artículo 2069). Leyes

\footnotetext{
30 Cfr. artículo 1708 del Código Civil. Tal sería el caso de la nulidad de matrimonio del artículo 99 del Código Civil y de la acción pauliana del artículo 2370 del Código Civil. Véase Vodanovic (1961, pág. 331).

${ }^{31}$ Es lo que se sigue del artículo 1 del Código Civil que señala, en su parte pertinente, que "[1]a ley es una declaración de la voluntad soberana que, manifestada en la forma prescrita por la Constitución, manda, prohíbe o permite".
} 
imperativas son las que mandan a una persona a hacer algo, las que le imponen una obligación de hacer. Tal es el caso de las leyes tributarias que obligan al pago de impuestos. Finalmente, leyes prohibitivas son aquellas mandan a abstenerse de hacer algo. Ejemplo de una ley prohibitiva es el artículo del Código Civil que prohíbe que en el mutuo se establezca la estipulación de intereses de intereses (artículo 2113). Según ha dicho la Corte Nacional de Justicia, las leyes imperativas se equiparan a las leyes prohibitivas cuando la causa que ha determinado su existencia es el equilibrio social, la moral pública o la armonía económica ${ }^{32}$.

El artículo 9 del Código Civil al hablar de "actos que prohíbe la ley" se refiere, pues, a los actos jurídicos que contravienen leyes prohibitivas y, según interpretación de la Corte Nacional de Justicia, también a los actos jurídicos que desobedecen una ley imperativa que ha sido establecida para proteger intereses de orden público.

Resuelto que el acto jurídico que contraviene una ley prohibitiva es nulo, falta contestar a la pregunta de qué tipo de nulidad es la que adolecen este tipo de actos, si nulidad absoluta o nulidad relativa.

Según una interpretación, la disposición contenida en el artículo 9 del Código Civil establece una norma general según la cual hay objeto ilícito y, por tanto, nulidad absoluta, en todos los casos en los que el acto jurídico contravenga alguna prohibición legalmente establecida (Alessandri Besa, 2011, págs. 49-50).

Según otra interpretación, desarrollada por la Corte Nacional de Justicia en un fallo de 1880, el artículo 9 del Código Civil contiene una disposición general que no puede ser entendida aisladamente y que debe ser concordada con el artículo 1698 del Código Civil que establece que hay nulidad absoluta cuando se omite algún requisito o formalidad que ha sido prescrito en consideración a la naturaleza del acto, y que hay nulidad relativa

\footnotetext{
${ }^{32}$ Cfr. Maza vs. Guamán et al., 25 de julio de 1998, Gaceta Judicial Serie XVI No. 12. En este mismo sentido, Alessandri Besa (2011, pág. 144).
}

Ius Humani, v. 3 (2012/13), p. 94 
cuando se omite un requisito que ha sido prescrito en consideración a la calidad o estado de las partes del acto. Si la prohibición legal que el acto ha contravenido ha sido establecida en consideración de la naturaleza del acto, hay nulidad absoluta; pero si la prohibición legal infringida ha sido establecida en consideración de las partes, hay nulidad relativa ${ }^{33}$.

Parece que esta última es la buena doctrina, desde que sería una inconsistencia con el sistema previsto en el Código Civil el declarar nulo absolutamente a un acto que la ley prohíbe con el sólo objeto de proteger a una de las partes y no de precautelar el orden público o el interés general.

En pocos puntos como éste las resoluciones de la Corte Nacional aparecen tan contradictorias e inconsistentes. No sólo porque se ha declarado la nulidad absoluta de actos prohibidos por el solo interés de una de las partes, sino porque el mismo concepto de leyes prohibitivas ha sido entendido de una manera extremadamente amplia. Así, por ejemplo, se ha aplicado el artículo 9 del Código Civil para concluir que la venta de un inmueble adolece de nulidad absoluta porque no se contó con la aprobación de un organismo estatal siendo esta aprobación legalmente requerida ${ }^{34}$, que es nula absolutamente la partición a la

${ }^{33}$ Cfr. Chiriboga vs. Román, 19 de junio de 1880, Gaceta Judicial Serie I, No. 1; 4 de febrero de 1924, Gaceta Judicial Serie IV, No. 137; Valdiviezo et al. vs. Vásquez et al., 27 de mayo de 1996, Registro Oficial No. 72 del 26 de mayo de 1997.

${ }^{34}$ Cfr. Sánchez vs. Sánchez, 24 de abril de 1997, Gaceta Judicial Serie XVI, No. 8; Maza vs. Herederos de Guamán, Gaceta Judicial Serie XVI, No. 12, donde se dice que las normas imperativas deben equiparse a las prohibitivas cuando la causa que ha determinado su existencia es el equilibrio social, la moral pública y la armonía económica. 
que no precede inventario de bienes ${ }^{35}$, que es nula de nulidad absoluta la compraventa entre cónyuges ${ }^{36}$.

\section{EFECTOS DE LA DECLARATORIA JUDICIAL DE NULIDAD}

\subsection{Sentencia que declara la nulidad de un acto}

La nulidad absoluta y la nulidad relativa se diferencian en cuanto a su fundamento, a las causales para su aplicación, a las personas que pueden alegarla, a la posibilidad de convalidarse y al tiempo para su saneamiento ${ }^{37}$. La nulidad absoluta y la nulidad relativa no se diferencian, en cambio, en cuanto a sus efectos (Vélez, 1924, pág. 421; Claro, 1979, págs. 629-630; Vodanovic, 1961, pág. 335). Una vez declarada judicialmente la nulidad, sea absoluta o relativa, la ley manda a que se vuelva al estado de cosas que precedía la celebración del acto. Considerando que los efectos de la declaratoria de nulidad absoluta y de nulidad relativa son los mismos, conviene tratarlos conjuntamente ${ }^{38}$.

En el derecho ecuatoriano, para que se entienda anulado un acto jurídico es necesario que haya una sentencia judicial con

${ }^{35}$ Cfr. Benítez vs. Fernández et al., 10 de noviembre de 1998, Gaceta Judicial Serie XVI, No. 13; López vs. Cauces et al., 22 de febrero de 1999, Gaceta Judicial Serie XVI, No. 14.

${ }^{36}$ Cfr. Freire vs. Narváez et al., 21 de octubre de 1999, Gaceta Judicial Serie XVII, No. 2.

${ }^{37}$ Recalcando estas diferencias, la Corte Nacional de Justicia ha llegado al extremo de sostener que la nulidad absoluta y la nulidad relativa no son acciones alternativas sino incompatibles, Contraloría General del Estado vs. Municipalidad de Cuenca et al., 18 de marzo de 2003, Gaceta Judicial Serie XVII No. 12.

${ }^{38}$ Es lo que hace la doctrina más citada en nuestras cortes (Vélez, 1924, pág. 417; Ospina \& Ospina, 2000, pág. 468; Claro, 1979, pág. 629; Vodanovic, 1961, pág. 335; Alessandri Besa, 2011, t. II, pág. 315; Valencia \& Ortiz, 2000, pág. 528).

Ius Humani, v. 3 (2012/13), p. 96 
efecto de cosa juzgada que declare la nulidad del acto ${ }^{39}$. Mientras dicha sentencia no exista, el acto surte sus efectos como si fuera válido y las partes no pueden excusarse de cumplir sus respectivas obligaciones (Ospina \& Ospina, 2000, pág. 470; Alessandri Besa, 2011, pág. 318$)^{40}$. Por eso se ha dicho que la sentencia de nulidad no es una sentencia meramente declarativa, sino que es constitutiva, en el sentido de que no se limita a señalar que una de las partes tiene un derecho, sino que crea, extingue o modifica un estado jurídico (Ospina \& Ospina, 2000, págs. 470-471) ${ }^{41}$.

Para que una sentencia judicial tenga por consecuencia la nulidad de un acto, deben cumplirse dos requisitos: a) la sentencia debe haber pasado en autoridad de cosa juzgada; y, b) la sentencia tiene que ser el resultado de un juicio seguido entre quienes eran legítimos contradictores (Ospina \& Ospina, 2000, pág. 471; Claro, 1979, pág. 633; Alessandri Besa, 2011, pág. 320).

El primer requisito es que la sentencia judicial tenga la fuerza y la autoridad de cosa juzgada. La cosa juzgada supone, básicamente, la inmutabilidad de la sentencia (Couture, 2009, pág. 341; Devis, 2009, pág. 641). Por tanto, una sentencia de nulidad contra la que todavía cabe el recurso extraordinario de casación no será base suficiente para anular los efectos de un acto jurídico, porque esta sentencia si bien está ejecutoriada, no hace fuerza de cosa juzgada, desde que puede ser modificada por la Corte Nacional de Justicia ${ }^{42}$.

${ }^{39}$ Cfr. artículo 1704 del Código Civil. A favor, Vélez (1924, págs. 417-418), Ospina \& Ospina (Ospina \& Ospina, 2000, pág. 470), Claro (1979, pág. 670), Vodanovic (1942, pág. 335), Alessandri Besa (2011, págs. 317-318). En contra para el caso de la nulidad absoluta, Baraona (2012, págs. 49-59).

${ }^{40}$ En contra para el caso de la nulidad absoluta, Baraona (2012, págs. 49-59).

41 Para una explicación sobre la diferencia entre sentencias meramente declarativas y constitutivas, cfr. Couture (2009, págs. 256-262). De nuevo, en contra Barona (2012, págs. 49-59).

${ }^{42}$ En obiter dictum de algunas sentencias de casación, la Corte Nacional de Justicia ha dicho que el recurso de casación cabe contra sentencias que tienen la autoridad de cosa juzgada formal y material. Sin embargo, el hecho de que la 
En segundo lugar, la sentencia tiene que haber sido el resultado de un juicio seguido entre legítimos contradictores. Según doctrina sentada por la Corte Nacional de Justicia, son legítimos contradictores en un juicio de nulidad las personas que celebraron el acto $^{43}$; si alguna parte estaba compuesta por más de una persona, habrá un caso de litisconsorcio necesario, pues sin la citación a todas esas personas, no podrá dictarse sentencia de fondo ${ }^{44}$. Por tanto, en el caso de un contrato de compraventa que se celebró entre dos compañías por un lado, y una persona natural por otro, el juicio de nulidad que se siga entre una de esas compañías y la persona natural, no podrá terminar con una sentencia de fondo por no haberse citado a la otra compañía. De lo que se concluye que sólo puede anularse un acto si la sentencia que lo anula es el resultado de un juicio en el que fueron citados todas las personas que celebraron el acto.

Conviene recalcar que el Código Civil señala que en el caso de que dos o más personas contraten con un tercero, la nulidad que se declare a favor de una de esas personas no podrá aprovechar a las otras (artículo 1707). La única interpretación consistente con la doctrina de litisconsorcio necesario de la Corte Nacional es la de que el Código Civil se refiere aquí solo a que una de las varias personas que contratan con el tercero tenga una causal de nulidad a su favor, que las otras no tienen. En este supuesto, la nulidad declarada a su favor no invalida el acto con respecto a las otras personas. Tal sería el caso de un contrato de arrendamiento firmado entre un arrendador y dos arrendatarios, de los cuales uno es incapaz y el otro no: el contrato sería válido

Corte Nacional pueda reformar el contenido de la sentencia que es objeto de casación y, por tanto, quitarle el carácter de "inmutable", hace a esa afirmación de la Corte, falsa y contradictoria.

${ }^{43}$ Cfr. Jumbo vs. Yaguache et al., 25 de junio de 1999, Gaceta Judicial, Serie XVII No. 1; Paz et al. vs. Guambaña et al., 28 de julio de 2003, Gaceta Judicial Serie XVII No. 13.

${ }^{44}$ Cfr. Jumbo vs. Yaguache et al., 25 de junio de 1999, Gaceta Judicial, Serie XVII No. 1. OSPINA, op. cit., pp. 474-475.

Ius Humani, v. 3 (2012/13), p. 98 
respecto de este último pero nulo en cuanto al primero, pero el juicio debió seguirse entre todos los contratantes.

Una vez declarada judicialmente la nulidad en una sentencia que tenga autoridad de cosa juzgada y que haya sido el resultado de un juicio entre legítimos contradictores, el acto se entiende anulado. La consecuencia de esta sentencia judicial será que las cosas vuelvan al estado que tenían antes de que el acto fuera celebrado, es decir, que las cosas queden como si el acto no se hubiese realizado jamás ${ }^{45}$. Esto último supondrá, básicamente, paralizar los efectos futuros del acto y destruir los efectos que el acto ya hubiera producido.

\subsection{Efectos de la nulidad entre las partes}

De acuerdo al Código Civil, la nulidad judicialmente declarada de un acto jurídico concede a las partes el derecho de ser restituidas a la misma situación que tenían antes de que el acto se hubiera celebrado (artículo 1704). Así, la regla es que la declaratoria de nulidad tiene un efecto retroactivo, pues hace volver al estado de cosas que precedía a la realización del acto. En virtud de esta regla, las partes tienen el derecho a volver exactamente a la misma situación patrimonial que tenían antes del acto: ni más ricos ni más pobres (Ospina \& Ospina, 2000, pág. 472; Claro, 1979, pág. 634; Vodanovic, 1961, pág. 335; Alessandri Besa, 2011, págs. 330-331).

Los efectos de la declaratoria de nulidad entre las partes difieren tratándose de actos cuyas obligaciones se han cumplido y actos cuyas obligaciones no se han cumplido.

En el caso de que las obligaciones no se hayan cumplido, la declaratoria de nulidad sirve como medio de extinción de obligaciones: exime a las partes del deber de ejecutar sus

${ }^{45}$ Cfr. Artículo 1704 del Código Civil. En apoyo, Vélez (Vélez, 1924, pág. 421), Valencia \& Ortiz (2000, pág. 528), Ospina \& Ospina (2000, pág. 471), Claro (1979, pág. 630), Vodanovic (1961, pág. 335), Alessandri Besa (2011, pág. 325). 
obligaciones, e impide exigir el cumplimiento de las obligaciones de su contraparte (Ospina \& Ospina, 2000, pág. 472; Claro, 1979, pág. 634; Vodanovic, 1961, pág. 336; Alessandri Besa, 2011, págs. 325-326; Valencia \& Ortiz, Derecho civil parte general y personas, 2000, pág. 528). Así, por ejemplo, si se anula un contrato de compraventa que todavía no se ha ejecutado, el comprador no tiene el deber de hacer la tradición de la cosa, ni el derecho a pedir el pago del precio.

En el caso de que las obligaciones se hayan cumplido, total o parcialmente, cada contratante debe devolver lo que haya recibido en virtud del acto nulo (Ospina \& Ospina, 2000, pág. 472; Claro, 1979, págs. 634-635; Vodanovic, 1961, pág. 336; Alessandri Besa, 2011, pág. 326). De acuerdo a lo establecido en el Código Civil, para estas restituciones deberán observarse las reglas de las prestaciones del poseedor vencido en una acción de reivindicación (artículo 1704) ${ }^{46}$. Así, si se anula un contrato de compraventa en el que se han ejecutado sus obligaciones, el vendedor deberá devolver el precio de la cosa y el comprador deberá regresar la cosa vendida. Si la cosa ha perecido en poder del vendedor por su culpa, deberán aplicarse las reglas de las restituciones mutuas, si hubo mala fe deberá pagar el comprador el precio de la cosa en dinero, y si hubo buena fe solamente en cuanto se haya aprovechado del perecimiento de la cosa.

Hay dos excepciones en el Código Civil a la regla de que la nulidad declarada judicialmente da derecho a las partes a volver al mismo estado que tenían antes de la celebración del acto.

La primera excepción, es que las partes no pueden repetir lo que han dado o pagado en razón de un objeto o causa ilícita a sabiendas (artículo 1704 del Código Civil). Así, si se declara nulo

\footnotetext{
${ }^{46}$ Las reglas de las prestaciones mutuas están en el Código Civil, a partir del artículo 948. En este sentido, Vélez (1924, pág. 422), Valencia \& Ortiz (2000, pág. 529), Ospina \& Ospina (2000, págs. 473-474), Claro (1979, págs. 634635), Vodanovic (1961, págs. 336-337) y Alessandri Besa (2011, págs. 330335).
}

Ius Humani, v. 3 (2012/13), p. 100 
por tener objeto ilícito al contrato mediante el cual se acordaba pagar una suma de dinero a cambio de que se disponga del derecho a suceder, la parte que pagó el dinero no podrá repetir lo dado.

La segunda excepción que trae el Código Civil se refiere a que si la causal de nulidad es la incapacidad de una de las partes, la otra parte no puede pedir restitución sino en cuanto probare que la persona incapaz se ha hecho más rica (artículo 1705). Así, por ejemplo, si una persona celebra un contrato de préstamo con un demente que está bajo interdicción judicial, y ese contrato luego se anula, no podrá pedirse la restitución del monto prestado si el demente despilfarró el dinero en apuestas, pero sí si se prueba en juicio que lo utilizó para cancelar alguna deuda o adquirir un bien que le sea de utilidad.

Como se ve, la acción de nulidad es básicamente una acción restitutoria: se busca que retorne al patrimonio de una persona lo que haya salido de él en virtud de un acto jurídico inválido. Así, si salió del patrimonio un bien inmueble en virtud de un contrato de compraventa nulo, el inmueble deberá regresar al patrimonio del vendedor y el precio pagado al patrimonio del comprador, siempre que no apliquen las dos excepciones que acabamos de revisar.

Sin embargo, según ha hecho notar recientemente la doctrina, a más de esta acción restitutoria a la que se refiere el Título XX del Libro IV del Código Civil, puede caber la acción por indemnización de daños y perjuicios (Baraona González, 2012, págs. 86-87). Por haberse declarado nulo el acto jurídico, se trataría de una acción por responsabilidad extracontractual (Alessandri Rodríguez, 1942, págs. 57-58), que tendría que cumplir con los requisitos de culpa, nexo causal y daño, y que buscaría ya no la restitución de lo dado en virtud del acto, sino la indemnización del perjuicio provocado por la parte que provocó la nulidad (Baraona González, 2012, págs. 49-59).

El fundamento legal de acumular la acción de nulidad a la acción de indemnización por daños y perjuicios puede encontrarse 
en el Libro II del Código Civil que, a propósito de la reivindicación, señala que, cuando resulte difícil localizar la cosa que se quiere reivindicar, la acción reivindicatoria también tendrá lugar contra quien enajenó la cosa que se busca reivindicar para que restituya lo que ha recibido por ella, y que en caso de que la haya enajenado sabiendo que era ajena, para la indemnización de perjuicio (artículo 942 del Código Civil) ${ }^{47}$.

En realidad esta acción de responsabilidad extracontractual se puede mostrar especialmente útil en aquellos casos en los que la restitución no sea suficiente para dejar indemne a una de las partes de un acto nulo. Así, por ejemplo, en el caso del contrato de mandato firmado como consecuencia del dolo del mandatario que se presentó como experto en negocios y no lo era, el mandante podría no estar satisfecho solamente con que se anule el contrato de mandato sino con que se le indemnice por los negocios que no pudo realizar a consecuencia de la ineptitud de su mandatario.

\subsection{Efectos de la nulidad con respecto a terceros}

El Código Civil sienta la regla general de que la nulidad judicialmente declarada da acción reivindicatoria contra terceros poseedores (artículo 1706). La sentencia que declara la nulidad de un acto tiene efecto retroactivo y, por tanto, se entiende que el acto no se ha producido jamás. Si se trata de un acto jurídico que supuso la transferencia de un bien a favor de un tercero, la consecuencia de la declaratoria judicial de la nulidad es que se entenderá que esa transferencia nunca se realizó y que el bien nunca salió del dominio de la parte que intervino en el acto nulo: resuelto el derecho del que da, resuelto el derecho de quien recibe (Ospina \& Ospina, 2000, págs. 478-479; Claro, 1979, págs. 637638; Vodanovic, 1961, pág. 338; Alessandri Besa, 2011, pág. 349; Valencia \& Ortiz, Derecho civil parte general y personas, 2000,

${ }^{47}$ Baraona cita este artículo como fundamento para la acción indemnizatoria (2012, págs. 86-87). 
pág. 529). Así, por ejemplo, si se declaró nula una compraventa en la cual el comprador, después de recibir la cosa, la vendió a un tercero, el tercero pierde su derecho a la cosa.

Según la opinión que ha sido tradicionalmente sostenida por la doctrina, la acción reivindicatoria procede contra terceros independientemente de que estén de buena o de mala fe; el Código Civil no hace diferencia (Ospina \& Ospina, 2000, pág. 478; Vodanovic, 1961, pág. 338; Alessandri Besa, 2011, pág. 350). Así, pues, deberá restituir la cosa el tercero que la compró pensando que su vendedor la tenía en virtud de un contrato válido, al igual que aquel que sabía que su vendedor poseía en virtud de un contrato nulo.

Sin embargo, parece más sensato sostener que la reivindicación no procede contra terceros de buena fe. Este es el criterio de un sector minoritario de la doctrina ${ }^{48}$, que encuentra soporte en el principio de respeto de las apariencias ${ }^{49}$ y en algunas disposiciones del Código Civil ${ }^{50}$. Mirado desde la perspectiva de quien adquiere algo en la justa creencia que lo adquiría lícitamente, aparece como una injusticia el privarlo de esa cosa en virtud de la nulidad de un acto jurídico que sólo es una causa remota de su adquisición.

Cualquiera sea la opinión que se sostenga, queda claro que la reivindicación contra terceros tiene la clara excepción de que éstos no hayan adquirido los bienes por prescripción adquisitiva (Ospina \& Ospina, 2000, pág. 479; Vodanovic, 1961, pág. 339; Alessandri Besa, 2011, pág. 356). Y así, si el tercero ha estado cinco años en posesión ordinaria de un inmueble, podrá evitar la

48 "[L]a declaración de nulidad deshace retroactivamente el negocio entre las partes; pero tal rescisión no es posible en relación con terceros de buena fe" (Valencia \& Ortiz, 2000, págs. 529-530).

${ }^{49}$ Ver lo dicho a propósito del acto jurídico putativo.

${ }^{50}$ A propósito de las obligaciones condicionales, los artículos 1506 y 1507 del Código Civil prescriben que si se enajena una cosa bajo condición y la condición llega a cumplirse, no se puede reivindicar la cosa contra terceros poseedores de buena fe. 
reivindicación demostrando que ha adquirido el bien por prescripción.

Se ha discutido si la acción reivindicatoria procede contra terceros que no hayan sido parte del juicio en que se declaró la nulidad del acto. Es claro que se puede acumular en un mismo juicio la acción de nulidad contra las partes del acto y la acción reivindicatoria contra los terceros poseedores (Ospina \& Ospina, 2000, pág. 477; Vodanovic, 1961, pág. 339; Alessandri Besa, 2011, pág. 353). Sin embargo, no queda del todo claro cuáles son las consecuencias de no incluir a esos terceros en el juicio. Según un sector de la doctrina, los terceros poseedores son legítimos contradictores y deben ser escuchados en juicio, pues, en caso contrario, se estaría afectando su derecho a la defensa ${ }^{51}$. Según otro sector, el Código Civil establece en la sentencia que declara la nulidad de un acto una excepción al principio de que el fallo sólo obliga a quienes han sido parte en el juicio, pues la nulidad tiene efecto retroactivo, y no es necesario contar con la presencia de los terceros poseedores cuando se discute la acción personal de nulidad en juicio (Ospina \& Ospina, 2000, págs. 477-478; Claro, 1979, pág. 637).

\section{Conclusiones}

La inexistencia, la nulidad absoluta y la nulidad relativa son piezas fundamentales en la doctrina jurídica y en la práctica del derecho.

En este trabajo se ha tratado de esbozar un resumen sobre las reglas que gobiernan a estas tres categorías en el derecho privado ecuatoriano. Se ha seguido, para el efecto, la aproximación clásica a la materia, que consiste en estudiar el régimen de la inexistencia, de la nulidad absoluta y de la nulidad

51 Es el criterio del chileno Alejandro Romero, citado por Alessandri Besa (2011, págs. 354-356).

Ius Humani, v. 3 (2012/13), p. 104 
relativa por separado, destacando las causales, la legitimación, el saneamiento y la necesidad de una sentencia judicial, en cada caso, siguiendo lo dispuesto en la legislación, lo fallado por las cortes y lo dicho por los autores más reconocidos en nuestro medio.

Este cuadro resume y compara los regímenes de estas tres categorías según las hemos estudiado:

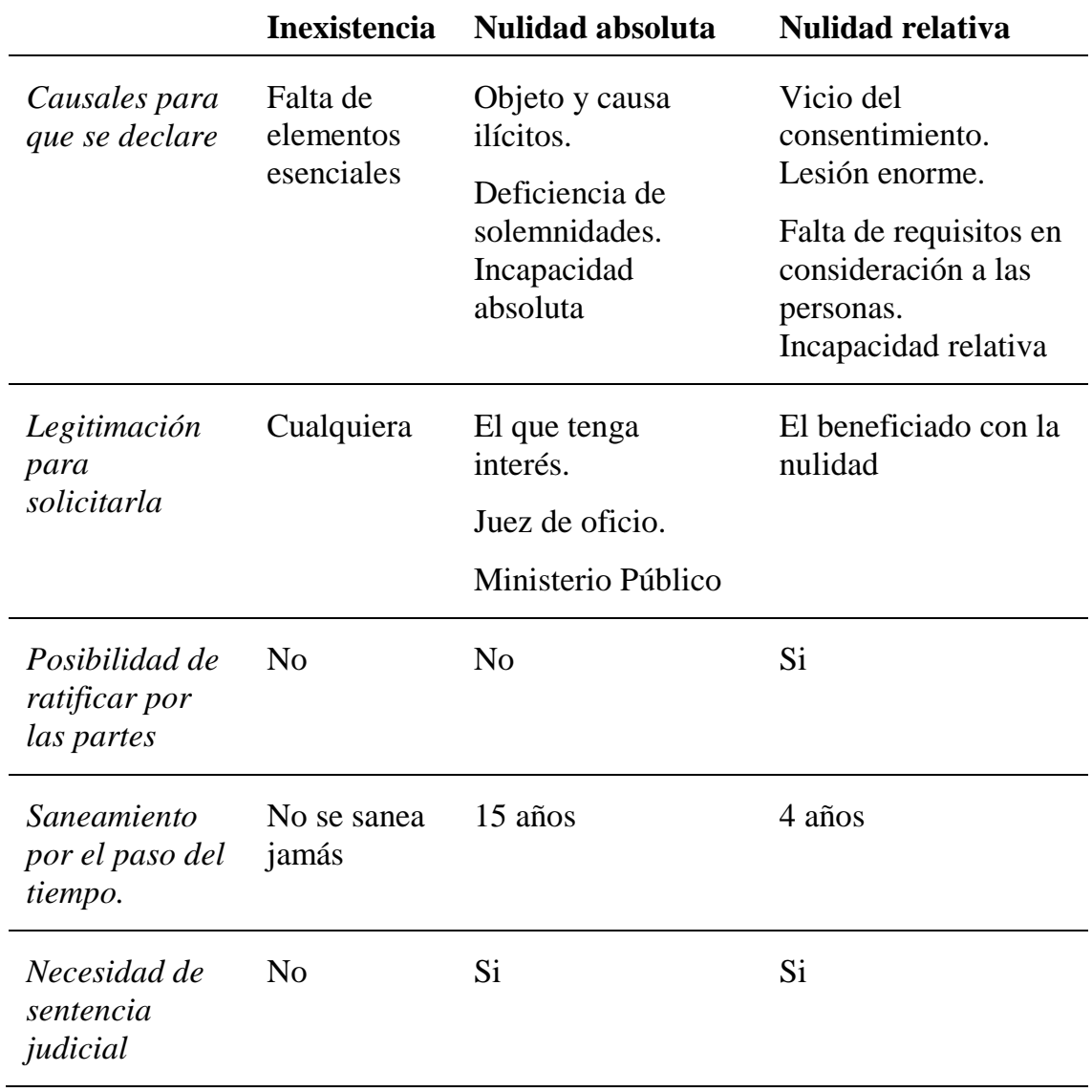


Este breve repaso de las reglas más básicas sobre estas instituciones, permite ver el bosque, aunque no los árboles. La frecuencia con que se presentan casos de inexistencia y de nulidad en la práctica jurídica de nuestro país vuelve imperiosa la necesidad de un estudio profundo sobre la materia en nuestro medio. Por lo pronto, este artículo puede ser una contribución a la edificación de ese estudio profundo. 


\section{REFERENCIAS}

Abeliuk, R. (2001). Las Obligaciones. Bogotá: Temis y Editorial Jurídica de Chile.

Aguilar vs. Servicios Hoteleros (8 de febrero de 2000).

Alessandri Besa, A. (2011). La nulidad y la rescisión en el derecho civil chileno. Santiago de Chile: Editorial Jurídica de Chile.

Alessandri Rodríguez, A. (1942). De la responsabilidad extracontractual en el Derecho civil chileno. Santiago de Chile: Imprenta Universitaria.

Baraona González, J. (2012). La nulidad de los actos jurídicos. Bogotá: Grupo Editorial Ibañez.

Betti, E. (2008). Teoría General del negocio Jurídico. Granada: Comares.

Bustos, J. (1999). La doctrina de la apariencia jurídica. Madrid: Dykinson.

Claro, L. (1979). Explicaciones de derecho civil y comparado. Santiago de Chile: Editorial Jurídica de Chile.

Couture, E. (2009). Fundamentos del Derecho Procesal Civil. Buenos Aires: B de F.

De Castro y Bravo, F. (2002). El negocio jurídico. Madrid: Civitas.

Devis, H. (2009). Nociones generales de derecho procesal civil. Bogotá: Temis.

Galgano, F. (1992). El negocio jurídico. Valencia: Tirant lo Blanch.

Guzmán, A. (2002). La Buena Fe en el Código Civil de Chile. Revista Chilena de Derecho, 29(1), 11-23.

Larrea, J., \& Merino, R. (2004). Derecho civil del Ecuador, vol. XI. Quito: Corporación de Estudios y Publicaciones.

Meza, R. (1974). De las obligaciones. Santiago de Chile: Editorial Jurídica de Chile.

Ospina, G., \& Ospina, E. (2000). Teoría general del contrato y del negocio jurídico. Bogotá: Temis.

Pothier, R. (2007). Tratado de las obligaciones. Buenos Aires: Heliasta.

Valencia, A. (1979). La posesión. Bogotá: Temis. 
Valencia, A., \& Ortiz, Á. (2000). Derecho civil parte general y personas. Bogotá: Temis.

Vélez, F. (1924). Estudios sobre el Derecho civil colombiano, tomo VI (2 ed.). París: Imprenta París-América.

Vodanovic, A. (1942). De las fuentes de las obligaciones. Santiago de Chile: Nascimento.

Vodanovic, A. (1961). Curso de Derecho Civil Parte General. Santiago de Chile: Nascimento.

Vodanovic, A. (2004). Tratado de las obligaciones. Santiago de Chile: Editorial Jurídica de Chile.

\section{Sentencias revisadas}

Aguilar vs. Servicios Hoteleros, 8 de febrero de 2001, Gaceta Judicial Serie XVII No. 4.

ALTABAR vs. Salgado, 16 de mayo de 2001, Gaceta Judicial Serie XVII No. 6 Arévalo et al. vs. Arévalo et al., 4 de junio de 2004, Gaceta Judicial Serie XVIII No. 1.

Aucapiña et al. vs. Ministerio de Educación y Cultura, 31 de enero de 2001, Gaceta Judicial Serie XVII No. 5.

Avilés et al. vs. Avilés et al., 22 de febrero de 2001, Gaceta Judicial Serie XVII No. 5

Barberán et al. vs Iriarte et al., 19 de mayo de 2003, Gaceta Judicial Serie XVII No. 12.

Benítez vs. Fernández, 10 de noviembre de 1998, Gaceta Judicial Serie XVI No. 15.

Borja vs. Campos, 8 de mayo de 1997, Gaceta Judicial Serie XVI No. 9.

Bravo vs. Palma, 18 de junio de 2002, Gaceta Judicial Serie XVII No. 9.

Bucaram vs. Chejin, 21 de noviembre de 1996, Gaceta Judicial Serie XVI No. 7.

Buendía vs. Silva et al., 27 de mayo de 2009, Gaceta Judicial Serie XVIII No. 7.

Cadena vs. Jaramillo, 29 de marzo de 1999, Gaceta Judicial Serie XVI No. 15. Ius Humani, v. 3 (2012/13), p. 108 
Calle et al. vs. Muñoz et al., 5 de febrero de 2002, Gaceta Judicial Serie XVII No. 8.

Carbo et al. vs. Vergara et al., 18 de abril de 2007, Gaceta Judicial Serie XVIII No. 5.

Cárdenas vs. Armijos et al., 25 de febrero de 2006, Gaceta Judicial Serie XVII No. 2.

Chela vs. Rea, 11 de diciembre de 1996, Gaceta Judicial Serie XVI No. 7.

Chiriboga vs. Román, 19 de junio de 1880, Gaceta Judicial Serie I, No. 1.

Contraloría vs. Municipalidad de Cuenca et al., 18 de marzo de 2003, Gaceta Judicial Serie XVII No. 12.

Cooperativa de Vivienda Los Chasquis vs. Aseguradora del Sur, 8 de diciembre de 2009, Gaceta Judicial Serie XVIII No. 7.

Dávila vs. Salgado, 19 de marzo de 1996, Gaceta Judicial Serie XVI No. 5.

Diez vs. Yagua, 30 de julio de 2002, Gaceta Judicial Serie XVII No. 10.

Delgado et al. vs. Guerrón, 27 de junio de 1996, Gaceta Judicial Serie XVI No. 6.

Espinoza vs. Asociación Mutualista de Ahorro y Crédito para la Vivienda Azuay, 16 de noviembre de 2001, Gaceta Judicial Serie XVII. No. 7.

Figueroa et al. vs. Herederos de Bejarano, 29 de agosto de 2002, Gaceta Judicial Serie XVII No. 10.

Flores vs. Cooperativa de Vivienda de Ibarra, 22 de abril de 2002, Gaceta Judicial Serie XVII No. 9.

Freire vs. Navarrete, 21 de octubre de 1999, Gaceta Judicial Serie XVII No. 2.

Freire vs. Primera Zona Naval de la Armada Nacional, 6 de marzo de 2007, Gaceta Judicial Serie XVIII No. 3.

Garzón et al. vs. Zambrano et al., 24 de abril de 2000, Gaceta Judicial Serie XVII No. 3.

Gómez et al. vs. Gordillo et al., 17 de febrero de 1999, Gaceta Judicial Serie XVI. No. 14.

González et al. vs. González et al., 15 de enero de 2007, Gaceta Judicial Serie XVIII No. 3. 
González vs. Banco de los Andes, 18 de julio de 1996, Gaceta Judicial Serie XVI No. 6.

Heredia vs. Cervantes et al., 24 de abril de 2006, Gaceta Judicial Serie XVIII No. 2.

Jaramillo et al. vs. Heredia et al., 26 de marzo de 2001, Gaceta Judicial Serie XVII No. 5.

Jiménez et al. vs. Coello, 10 de octubre de 2002, Gaceta Judicial Serie XVII No. 10.

Layedra vs. Fuenmayor et al., 9 de abril de 2007, Gaceta Judicial Serie XVIII No. 5.

López et al. vs. Cauces et al., 22 de febrero de 1999, Gaceta Judicial Serie XVI No. 14.

López vs. López, 21 de febrero de 2003, Gaceta Judicial Serie XVII No. 11.

López vs. Pozo, 7 de julio de 1998, Gaceta Judicial Serie XVI No. 12.

Maza vs. Guamán, 25 de julio de 1998, Gaceta Judicial Serie XVI No. 12.

Mejía vs. Mejía et al., 28 de enero de 2003, Gaceta Judicial Serie XVII No. 12.

Mero et al. vs. Mero et al., 10 de marzo de 1998, Gaceta Judicial Serie XVI No. 11.

Miranda et al. vs. Pastor et al., 10 de febrero de 2005, Gaceta Judicial Serie XVIII No. 1.

Mirsky vs. Martinez, 17 de diciembre de 2003, Gaceta Judicial Serie XVII No. 14.

Montaño vs. Montaño, 16 de septiembre de 2004, Gaceta Judicial Serie XVIII No. 1.

Moreno vs. Superintendencia de Compañías y Citisur, 26 de octubre de 1998, Gaceta Judicial Serie XVI No. 13.

Municipio de Jipijapa vs. Toala et al., 25 de junio de 2004, Gaceta Judicial Serie XVIII No. 1.

Municipio de Quito vs DESACI, 9 de abril de 1996, Gaceta Judicial Serie XVI No. 5.

Municipio de Quito vs. DESACI, 28 de octubre de 1999, Gaceta Judicial Serie XVII No. 2. 
Ojeda vs. Luna, 3 de febrero de 2004, Gaceta Judicial Serie XVII No. 15.

Ortega vs. Burgos, 15 de septiembre de 1998, Gaceta Judicial Serie XVI. No. 13.

Parra vs. Samaniego, 14 de febrero de 2006, Gaceta Judicial Serie XVIII No. 2.

Paucra vs. Cruz, 22 de julio de 2002, Gaceta Judicial Serie XVII No. 10.

Paz et al. vs. Guambaña et al., 28 de julio de 2003, Gaceta Judicial Serie XVII No. 13.

Pérez et al. vs Hinojosa, 3 de marzo de 2006, Gaceta Judicial Serie XVIII No. 2.

Platzer vs. Platzer, 3 de diciembre de 1997, Gaceta Judicial Serie XVI No. 10.

Ponce vs. Amigos del Ecuador, 31 de octubre de 1995, Gaceta Judicial XVI No. 4.

Procurador General de la Nación vs. Fundación para la Educación y el Desarrollo, 15 de mayo de 1980, Gaceta Judicial Serie XIII No. 8.

Quirindumbay et al. vs. Japa et al., 6 de abril de 2009, Gaceta Judicial Serie XVIII No. 7.

Rengel vs Balseca et al., 14 de mayo de 1999, Gaceta Judicial Serie XVI No. 2.

Romero vs. Aguirre et al., 10 de enero de 2007, Gaceta Judicial Serie XVIII No. 3.

Romero vs. Medina, 1 de julio de 2004, Gaceta Judicial Serie XVIII No. 1.

Romero vs. Silva, 3 de abril de 2001, Gaceta Judicial Serie XVII No. 5.

Romero vs. Vicariato Apostólico, 3 de octubre de 2000, Gaceta Judicial Serie XVII No. 4.

Romo vs. Brito et al., 12 de julio de 2004, Gaceta Judicial Serie XV No. 15.

Sánchez vs. Sánchez et al., 24 de abril de 1997, Gaceta Judicial Serie XVI No. 8.

Solís vs. Aguilar et al., 14 de octubre de 2004, Gaceta Judicial Serie XVIII No. 1.

Sper vs. López, 23 de enero de 2007, Gaceta Judicial Serie XVIII No. 3. 
Tenenpaguay vs. Tenencota, 26 de abril de 2002, Gaceta Judicial Serie XVII No. 8.

Toledo vs. SICOMESA, 13 de abril de 1998, Gaceta Judicial Serie XVI No. 11.

Torres vs. Sánchez et al., 23 de septiembre de 2002, Gaceta Judicial Serie XVII No. 10.

Ulloa et al. vs. Filanbanco et al., Gaceta Judicial Serie XVII No. 10.

Valdiviezo et al. vs. Vásquez et al., 27 de mayo de 1996, Registro Oficial No. 72 del 26 de mayo de 1997.

Vélez vs. Solórzano, 21 de enero de 1998, Gaceta Judicial Serie XVI No. 12.

Wong vs. Bolivariano, 6 de mayo de 2004, Gaceta Judicial Serie XVII No. 14.

Yépez vs. Wood Vacation, 29 de agosto de 2001, Gaceta Judicial Serie XVII No. 7.

Zambrano et al. vs. López, 23 de febrero de 1999, Gaceta Judicial XVII No. 5.

Zamora vs. Zamora, 23 de abril de 1998, Gaceta Judicial Serie XVI No. 12.

Zhuzhingo vs. Siranaula, 21 de noviembre de 2003, Gaceta Judicial Serie XVII No. 14.

Zúñiga vs Arias, 22 de enero de 2002, Gaceta Judicial Serie XVII No. 7. 